\title{
Inhibition of epidermoid carcinoma A43I cell growth and angiogenesis in nude mice by early and late treatment with a novel dextran derivative
}

\author{
M Di Benedetto ${ }^{*, 1}$, A Starzec ${ }^{2}$, R Vassy ${ }^{2}$, GY Perret ${ }^{2}$, M Crépin ${ }^{1,3}$ and M Kraemer' \\ 'Laboratoire d'Oncologie Cellulaire et Moléculaire, UPRES 2360, Université Paris 13, 74 rue Marcel Cachin, 93017 Bobigny cedex, France; \\ ${ }^{2}$ Laboratoire de Pharmacologie, UPRES 2360, Université Paris 13, 74 rue Marcel Cachin, 93017 Bobigny cedex, France; \\ ${ }^{3}$ Laboratoire d'Hémostase, Endothélium et Angiogénèse, Unité INSERM 553, Hôpital Saint-Louis, 750 I 0 Paris, France
}

\begin{abstract}
We investigated the effect of a new dextran derivative, phenylacetate carboxymethyl benzylamide dextran ( $\mathrm{NaPaC}$ ), on epidermoid carcinoma A43I cells secreting a large quantity of angiogenic factor, vascular endothelial growth factor (VEGF). In vitro, NaPaC inhibited the proliferation of $\mathrm{A} 43 \mathrm{I}$ cells $\left(\mathrm{IC}_{50}=5 \mu \mathrm{M}\right)$. Also, $\mathrm{NaPaC}$ decreased the binding of radiolabelled $\mathrm{VEGF}_{165}$ to endothelial cells $\left(\mathrm{IC}_{50}=0.2 \mu \mathrm{M}\right)$. In vivo, we explored the effects of $\mathrm{NaPaC}\left(15 \mathrm{mg} \mathrm{kg}^{-1}\right)$ on $\mathrm{A} 43 \mathrm{I}$ xenograft growth starting the drug administration at the time of tumour cell inoculation (early treatment) and I week later, when tumours were well established (late treatment). Early treatment was more efficient on tumour inhibition ( $70 \%$ vs control) than late treatment ( $50 \%$ vs control). Early and late $\mathrm{NaPaC}$-treatment increased the aponecrosis in tumour by 70 and $30 \%$, respectively. Whatever treatment, $\mathrm{NaPaC}$ inhibited the intratumour endothelial cell density in the same manner. In contrast, vessel area was decreased only when $\mathrm{NaPaC}$ was injected early (35\%). These results show that $\mathrm{NaPaC}$ has a potent inhibitory effect, dependent on treatment outset, on epidermoid carcinoma growth associated with an intratumour microvascular network diminution and an aponecrosis increase. As this drug is nontoxic at efficient dose, it offers interesting perspectives for the therapy of malignant lesions.
\end{abstract}

British Journal of Cancer (2003) 88, 1987-1994. doi: I0.1038/sj.bjc.6600985 www.bjcancer.com

(C) 2003 Cancer Research UK

Keywords: tumour angiogenesis; phenylacetate carboxymethyl benzylamide dextran ( $\mathrm{NaPaC}$ ); aponecrosis; vascular endothelial growth factor (VEGF)

Angiogenesis, the formation of new blood vessels from established vessels, occurs under a variety of normal and pathological conditions. Also, it is a requisite for tumour growth and metastasis dissemination (Blood and Zetter, 1990; Ramanujan et al, 2000). The delivery of blood-borne nutrients to the tumour cells is essential for their survival and spread. Thus induction of angiogenesis was observed to precede the development of invasive tumours (Weidner et al, 1991).

We recently demonstrated in vitro that phenylacetate carboxymethyl benzylamide dextran $(\mathrm{NaPaC})$ inhibited the secretion of growth factors from breast cancer cells and prevented the action of growth factors by interacting with them (Di Benedetto et al, 2002). In particular, we showed that $\mathrm{NaPaC}$ formed complexes with vascular endothelial growth factor $\left(\mathrm{VEGF}_{165}\right)$, which is a specific mitogenic factor for endothelial cells. Vascular endothelial growth factor is the best-characterised VEGF-A form the expression of which has been correlated, temporally and/or spatially, with the onset of angiogenesis in a variety of tumours including lung (Senger et al, 1986), breast (Krantz et al, 1999), ovarian (Shen et al, 2000) and colon cancer (Cascinu et al, 2000).

\footnotetext{
*Correspondence: Dr M Di Benedetto;

E-mail: melanie.dibenedetto@ibl.fr

Received 27 December 2002; revised 10 March 2003; accepted 18 March 2003
}

In this report, we investigated the effect of $\mathrm{NaPaC}$ on the in vitro and in vivo growth of epidermoid carcinoma A431 cells that secrete a large amount of VEGF (Myoken et al, 1991). First, we explored in vitro if $\mathrm{NaPaC}$ could inhibit the $\mathrm{A} 431$ cell proliferation and prevent the binding of $\mathrm{VEGF}_{165}$ on tumour and endothelial cells. Then in vivo, we assessed the effects of $\mathrm{NaPaC}$ on the A431 tumour growth, cell death and microvascular system development in xenografts implanted in nude mice. Since angiogenesis occurred as specific spatiotemporal events (Mori et al, 1999) and since distinct antiangiogenic drugs have been shown to be effective at different stages of tumorigenesis (Bergers et al, 1999), we have studied and compared the tumours from animals treated with $\mathrm{NaPaC}$ starting at early or late stage of xenograft development.

\section{MATERIALS AND METHODS}

\section{Dextran derivative preparation}

New dextran derivative, phenylacetate carboxymethyl benzylamide dextran (Figure 1), named $\mathrm{NaPaC}$, was synthesised by Biodex Laboratory (Supplier) (Levallois-Perret, France) performing a statistical esterification of carboxymethyl benzylamide dextran with phenylacetic acid (Avramoglou et al, 2001). After purification by ultrafiltration (purity $>98 \%$ ) and lyophilisation, the chemical composition or degree of substitution (ds) of $\mathrm{NaPaC}$ was 


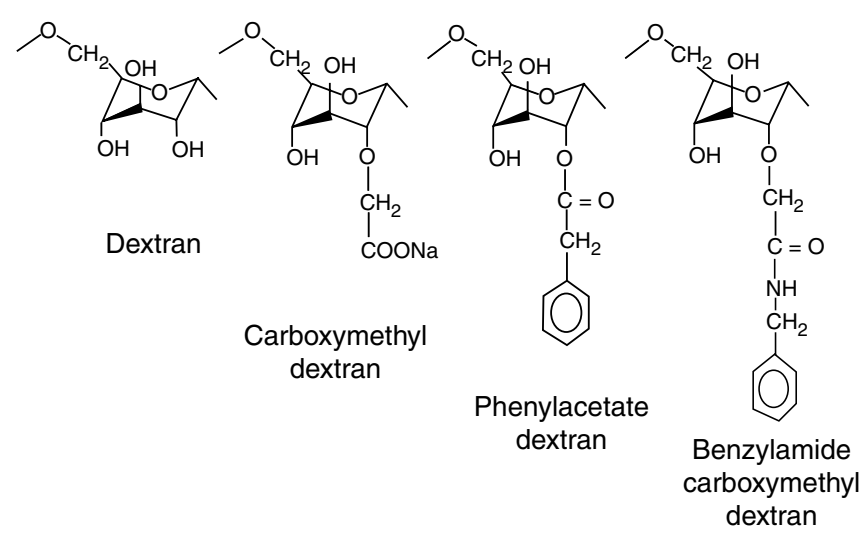

Figure I Structure of $\mathrm{NaPaC}$.

determined by acidimetric titration and elementary analysis of nitrogen. The composition of $\mathrm{NaPaC}$ was: $0 \mathrm{ds}$ for dextran, $0.67 \mathrm{ds}$ for carboxymethyl and $0.39 \mathrm{ds}$ for benzylamide and a phenylacetate ds of 0.35 . The calculated average molecular weight of $\mathrm{NaPaC}$ mer was $264.1 \mathrm{gU}^{-1}$. Absolute molecular weight was calculated multiplying the average molecular weight by the number of units (247). This calculation leads to MW: $77607 \mathrm{~g} \mathrm{~mol}^{-1}$.

\section{Cell culture}

Human epidermoid carcinoma A431 cells and human umbilical vein endothelial cells (HUV-EC) were purchased from American Tissue Culture Collection (Rockville, MD, USA). They were routinely grown in DMEM (Life Technologies, Inc., Gaithersburg, MD, USA), supplemented with $10 \%$ FCS, $2 \mathrm{mM}$ L-glutamine, $1 \mathrm{~mm}$ sodium pyruvate, $50 \mathrm{U} \mathrm{ml}^{-1}$ penicillin and $50 \mathrm{mg} \mathrm{ml}^{-1}$ streptomycin (all obtained from Life Technologies, Inc.), at $37^{\circ} \mathrm{C}$ in a $5 \%$ $\mathrm{CO}_{2}$-humidified atmosphere.

\section{Cell growth assays}

A431 cell growth was assessed using the MTT-microculture tetrazolium assay (Mosmann, 1983). Briefly, the cells $\left(4 \times 10^{3}\right)$ were incubated in $2 \%$ FCS-DMEM for $24 \mathrm{~h}$ and then treated with $\mathrm{NaPaC}$ at different concentrations for $72 \mathrm{~h}$. Then, the cells were washed with phosphate buffer saline (PBS) and incubated with $0.1 \mathrm{ml}$ of MTT $\left(2 \mathrm{mg} \mathrm{ml}^{-1}\right)$ for $4 \mathrm{~h}$.

\section{Binding competition assay}

HUV-EC and A431 cells were grown until $80 \%$ confluence in 24well tissue culture plates (Falcon, Strasbourg, France). After an overnight incubation in serum-free medium and two washings with ice-cold binding buffer (PBS, $0.2 \%$ gelatine), cells were incubated at $4{ }^{\circ} \mathrm{C}$ for $2 \mathrm{~h}$ in $0.3 \mathrm{ml}$ of binding buffer containing $7 \mathrm{pM}$ ${ }^{125} \mathrm{I}_{-} \mathrm{VEGF}_{165}$ (Amersham Pharmacia Biotech, Orsay, France) in the presence or absence of $\mathrm{NaPaC}$ at increasing concentrations $(0-24 \mu \mathrm{M})$. Incubation was arrested by gently removing the medium and washing the cell monolayer three times with icecold binding buffer. The radioactivity bound to cells was measured in gamma counter (LKB 1261 Multigamma) after cell lysis in $0.3 \mathrm{ml}$ of $0.5 \mathrm{~N} \mathrm{NaOH}$ for $30 \mathrm{~min}$. Nonspecific binding was determined in the presence of an excess ( $5 \mathrm{nM}$ ) of unlabelled VEGF 165 (R\&D Systems, Abingdon, UK). For the Scatchard plot analysis (Scatchard, 1986), binding was accomplished with increasing concentrations of unlabelled $\mathrm{VEGF}_{165}(0-5000 \mathrm{pm})$ and $7 \mathrm{pm}{ }^{125} \mathrm{I}-$ VEGF $_{165}$ in the presence or absence of $\mathrm{NaPaC}$ at $\mathrm{IC}_{50}$. Each curve was analysed according to the Scatchard procedure or by fitting a logistic curve (Graph Pad Software). All analyses were performed twice and carried out in triplicate.

\section{Xenografts in nude mice}

All in vivo experiments were carried out with ethical committee approval and met the standards required by the UKCCCR guidelines (Workman et al, 1998). A431 cells $\left(1 \times 10^{5}\right)$ were inoculated subcutaneously (s.c.) near the right mammary fad pad of 4-week-old athymic nude mice (nu/nu, $n=40$ ) (Harlan Laboratory, Gannat, France). Animals were kept in a temperature-controlled room on a 12:12 light-dark schedule with food and water ad libitum. Phenylacetate carboxymethyl benzylamide dextran was administrated following two protocols starting at early or late stage of xenograft development. In the first treatment, the administration of $\mathrm{NaPaC}\left(15 \mathrm{mg} \mathrm{kg}^{-1}, n=10\right)$ begun at the time of A431 cell inoculation: the tumour cells were injected s.c. in $0.1 \mathrm{ml}$ of $\mathrm{NaPaC}$ solution. In the control group $(n=10)$, the A431 cells were injected in $0.1 \mathrm{ml}$ of $0.9 \% \mathrm{NaCl}$. The drug or $0.9 \% \mathrm{NaCl}$ solution was administrated twice a week for 5 weeks. In the other protocol (late), the $\mathrm{NaPaC}$ treatment started 1 week after cell inoculation when palpable tumours have been developed. It is noteworthy that these tumours were observed in 20 out of 20 animals. Then, mice were arbitrarily placed in control $(n=10)$ and $\mathrm{NaPaC}$-treated group $(n=10)$. Phenylacetate carboxymethyl benzylamide dextran $\left(15 \mathrm{mg} \mathrm{kg}^{-1}\right)$ was injected in $0.1 \mathrm{ml}$ of $0.9 \% \mathrm{NaCl}$ s.c. near the tumour, twice a week for 5 weeks. Control received $0.1 \mathrm{ml}$ of $0.9 \% \mathrm{NaCl}$. Tumour volumes were calculated as previously described (Di Benedetto et al, 2001). In our experiment, we have used $\mathrm{NaPaC}$ at doses previously reported to be efficient on breast cancer cells xenografted in nude mice (Di Benedetto et al, 2002).

\section{Endothelial cell staining in tumour sections}

Tumour specimens were fixed with a solution of paraformaldehyde (4\%) and included into paraffin using standard procedure. Routinely, $5 \mu \mathrm{m}$ sections were stained in haematoxylin and eosin. For immunohistochemical studies, the sections were deparaffinised and rehydrated. Endogenous peroxidase was inactivated with $3 \% \mathrm{H}_{2} \mathrm{O}_{2}$. After washing in TBS $(0.05 \mathrm{M}$ Tris, $1.5 \mathrm{M} \mathrm{NaCl}, \mathrm{pH} 7.6)$, the tumour sections were preincubated with $10 \%$ normal goat serum for $1 \mathrm{~h}$ at room temperature. Endothelial cells were specifically labelled with GSL-1 isolectin B4 (Vector Laboratories, Burlingame, CA, USA). The GSL-1 lectin binds specifically to galactosyl residues and thus labels the mouse endothelial cells (Alroy et al, 1987). The sections were labelled for $1 \mathrm{~h}$ with the $1: 50$ diluted GSL-1 isolectin at room temperature, then incubated with goat antibody against GSL- 1 isolectin $\mathrm{B}_{4}$ (1:400 dilution, Vector Laboratories) for $30 \mathrm{~min}$, washed with TBS and incubated with biotinylated rabbit anti-goat immunoglobulins (1:400 dilution; Dako, Glostrup, Denmark) for $20 \mathrm{~min}$ in a moist chamber at room temperature. After three washes with TBS, samples were incubated with streptavidin-biotin peroxidase (LSAB kit; Dako) for $10 \mathrm{~min}$ using 3-amino-9-ethylcarbazole (AEC) chromogen, giving a red staining. Finally, slides were washed in water and counterstained with haematoxylin.

\section{Microvessel analysis in tumour sections}

Intratumour number of endothelial cells per tumour section area (endothelial cell density) was determined using a point-counting grid over the GSL-1-labelled cells (96 points in the grid corresponding to an area of $1.02 \mathrm{~mm}^{2}$ on the picture) (Weibel, 1979). For each tumour, 10 randomly selected nonserial sections were studied. For each section, 10 fields containing exclusively viable tumour cells, as indicated by the haematoxylin staining, were selected randomly for analysis. Using a Reichter-Jung 
(Polivar, Austria) microscope, each tumour was scanned at $\times 100$ magnification to select the regions with the most intense vascularisation following the criteria previously defined (Weidner et al, 1991). For each region, at least two pictures were taken at $\times 250$ magnification. The highest number of endothelial cells identified within any $\times 250$ field $\left(1.02 \mathrm{~mm}^{2}\right)$ was taken into account. The coefficient of variation (SD) was used to assess the variability of counts divided by field number of the same tumour. Mean intratumour endothelial cell numbers per area in the various tumours were compared using Student's $t$-test. To estimate the area of vessels in tumour section, the lumens bordered with at least one GSL-1-stained endothelial cell were counted using the pointcounting grid. The intratumour vessel area was expressed as the ratio of determined counts to total points of grid (96) according to Weibel method (Weibel, 1979). Thus, vessel area represents the fraction of the total tissue area occupied by the wall or lumen and reflects the overall number and size of vessels. For all statistical analyses, the level of significance was set at 0.05 .

\section{Cell death detection and quantification in tumour sections}

Tumour sections $(5 \mu \mathrm{m})$ were deparaffinised and rehydrated, then analysed for cell death DNA fragmentation using TumorTACS kit (R\&D Systems, Abington, UK). Intratumour aponecrotic cells were counted using a point-counting grid over the apoptotic cells as described above for endothelial cells. For each tumour section, 10 different fields were selected for analysis.

\section{Statistical analysis}

Multiple statistical comparisons were performed using ANOVA in a multivariable linear model. Some statistical analyses were performed using the Mann-Whitney $t$-test. $P<0.05$ was considered statistically significant.

\section{RESULTS}

\section{$\mathrm{NaPaC}$ inhibits the in vitro proliferation of epidermoid carcinoma A431 cells}

We have recently shown that $\mathrm{NaPaC}$ has an antiproliferative effect on various breast cancer cells (Di Benedetto et al, 2002). Here, we demonstrated that $\mathrm{NaPaC}$ is able to inhibit the in vitro growth of epidermoid carcinoma A431 cells in a dose-dependent manner

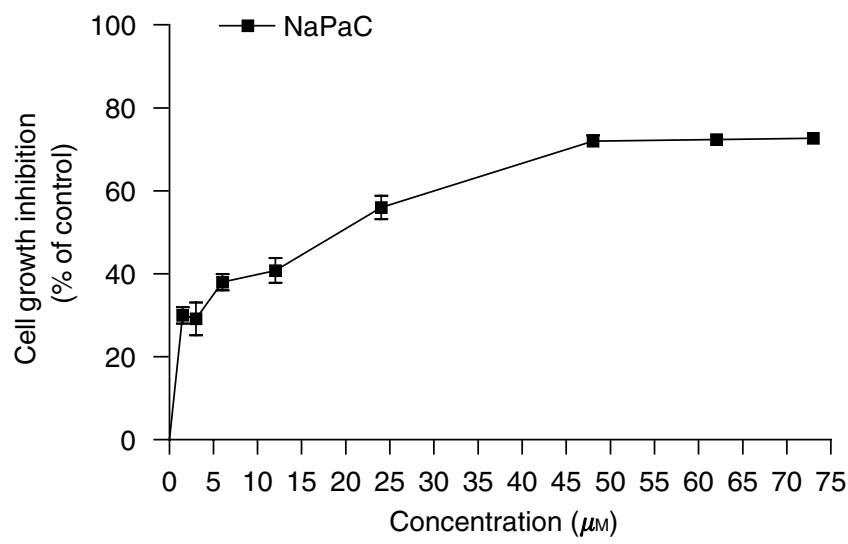

Figure 2 Phenylacetate carboxymethyl benzylamide dextran inhibits the A43I cell proliferation. Cells were incubated for $72 \mathrm{~h}$ in the absence or presence of $\mathrm{NaPaC}$ at various concentrations. Cell growth was assessed using MTT-assay as described in Materials and Methods. Each point represents the mean \pm s.d. of three independent experiments.
(Figure 2). After a $72 \mathrm{~h}$ incubation, the maximal inhibitory effect (70\%) was achieved in the presence of $48 \mu \mathrm{m} \mathrm{NaPaC}(P=0.03)$. The $\mathrm{NaPaC}$ concentration inducing $50 \%$ of maximal inhibition $\left(\mathrm{IC}_{50}\right)$ was $5 \mu \mathrm{M}$.

\section{Phenylacetate carboxymethyl benzylamide dextran inhibits VEGF $_{165}$ binding to A431 cells}

As we recently showed that $\mathrm{NaPaC}$ forms a complex with $\mathrm{VEGF}_{165}$ (Di Benedetto et al, 2002) and as A431 cells secrete high amounts of $\mathrm{VEGF}_{165}$ (Myoken et al, 1991) we tested, here, the effect of $\mathrm{NaPaC}$ on the binding of VEGF to A431 cells (Figure 3).
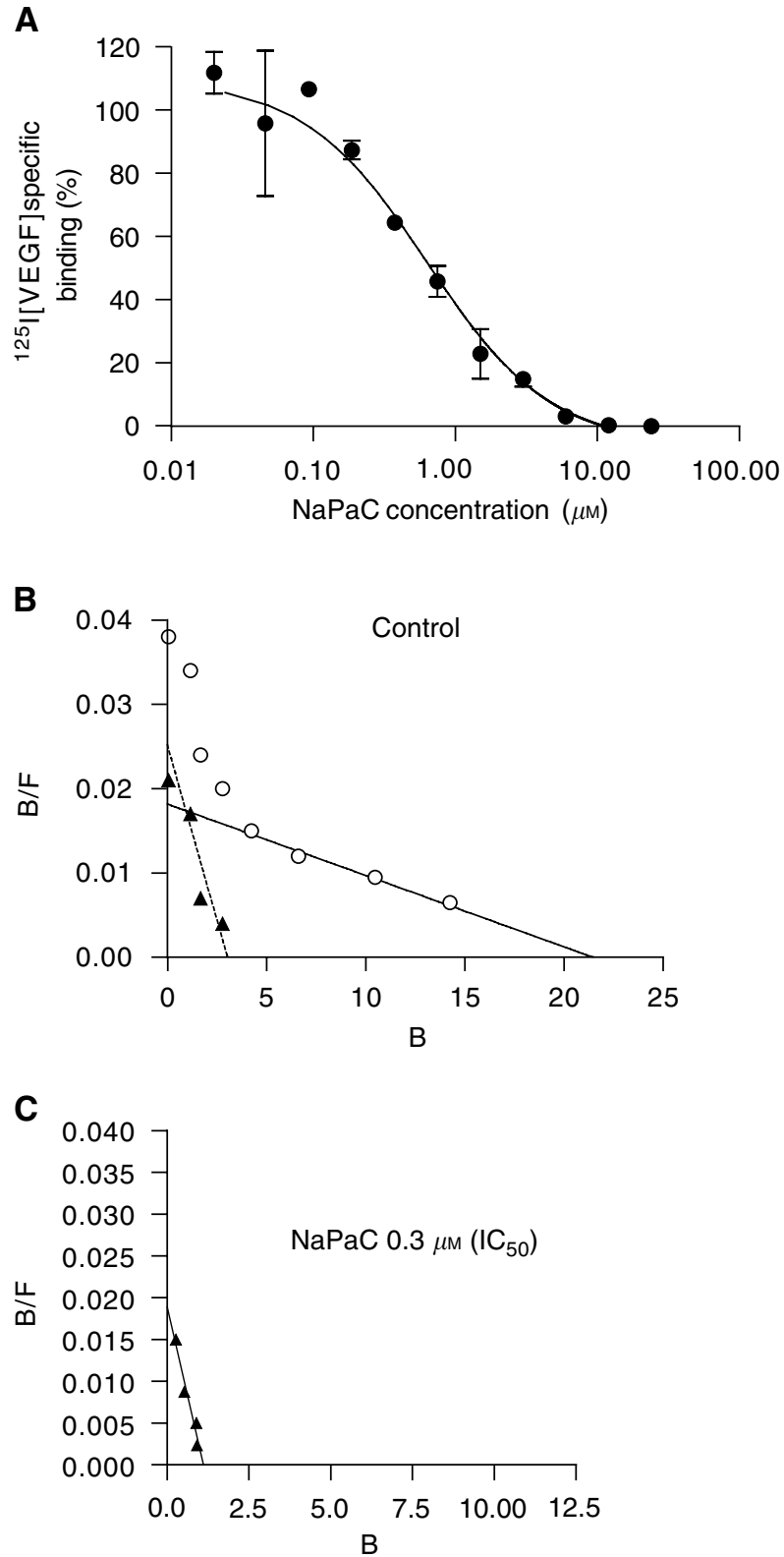

Figure $3 \mathrm{NaPaC}$ inhibits the $\mathrm{VEGF}_{165}$ binding to $\mathrm{A} 43 \mathrm{I}$ cells. (A) Cells were incubated with a fixed concentration of [ ${ }^{25}$ I]VEGF 165 (7 pM) in the absence or presence of $\mathrm{NaPaC}$ at various concentrations $(0.0375-24 \mu \mathrm{M})$. (B, C) Scatchard analysis was performed using $7 \mathrm{pM}\left[{ }^{125} \mid\right] \mathrm{VEGF}_{165}$ and unlabelled VEGF 165 at various concentrations in the absence (B) or presence $(\mathbf{C})$ of $0.3 \mu \mathrm{M} \mathrm{NaPaC}\left(\mathrm{IC}_{50}\right)$. 
Phenylacetate carboxymethyl benzylamide dextran inhibited the binding of $\mathrm{VEGF}_{165}$ to A431 cells in a concentration-dependant manner with an $\mathrm{IC}_{50}$ of $0.3 \mu \mathrm{M}$ (Figure $3 \mathrm{~A}$ ). The binding of $\mathrm{VEGF}_{165}$ was completely abolished by $6 \mu \mathrm{m} \mathrm{NaPaC}$. For Scatchard analysis, the cells were incubated with radiolabelled $\operatorname{VEGF}_{165}(7 \mathrm{pM})$ and unlabelled $\mathrm{VEGF}_{165}$ at increasing concentrations in the presence (Figure $3 \mathrm{C}$ ) or in the absence (Figure $3 \mathrm{~B}$ ) of $0.3 \mu \mathrm{M} \mathrm{NaPaC}\left(\mathrm{IC}_{50}\right)$. In control conditions (in the absence of $\mathrm{NaPaC}$ ), two classes of binding sites were observed. The higher affinity class is characterised by a $K_{\mathrm{d}}$ of $100 \mathrm{pm}$ and the lower affinity population by a $K_{\mathrm{d}}$ of $1200 \mathrm{pm}$. The addition of $0.3 \mu \mathrm{M}\left(\mathrm{IC}_{50}\right) \mathrm{NaPaC}$ did not significantly affect the affinity of the first class sites, but induced the disappearance of the low-affinity population (Figure 3C). This can be explained by the fact that $\mathrm{NaPaC}$ at $\mathrm{IC}_{50}$ formed a complex only with a fraction of $\mathrm{VEGF}_{165}$, thus decreasing the concentration of the remaining available growth factor below the level required for binding to low-affinity sites. At higher concentration $(6 \mu \mathrm{M})$, $\mathrm{NaPaC}$ was able to block $\mathrm{VEGF}_{165}$ binding to high-affinity sites since no specific binding was observed (Figure 3A). These experiments clearly showed that $\mathrm{NaPaC}$ prevented the $\mathrm{VEGF}_{165}$ binding to A431 cells involving, at least in part, interactions with the growth factor.

\section{Phenylacetate carboxymethyl benzylamide dextran inhibits the $\mathrm{VEGF}_{165}$ binding to human umbilical vein endothelial cells}

Phenylacetate carboxymethyl benzylamide dextran inhibited the binding of $\mathrm{VEGF}_{165}$ to human umbilical vein endothelial cells (HUV-EC) in a concentration-dependant manner with an $\mathrm{IC}_{50}$ of $0.2 \mu \mathrm{M}$ (Figure 4). The binding of $\mathrm{VEGF}_{165}$ was completely abolished by $6 \mu \mathrm{M} \mathrm{NaPaC}$. Scatchard analysis revealed in control conditions (in the absence of $\mathrm{NaPaC}$ ), two classes of binding sites as observed by others (Soker et al, 1996; Li et al, 2001). The higher affinity class is characterised by a $K_{\mathrm{d}}$ of $355 \mathrm{pm}$ and the lower affinity population by a $K_{\mathrm{d}}$ of $1000 \mathrm{pm}$. The addition of $0.2 \mu \mathrm{m}$ of $\mathrm{NaPaC}\left(\mathrm{IC}_{50}\right)$ did not significantly affect the affinity of the first class sites, but induced the disappearance of the low-affinity population (data not shown). The disappearance of high-affinity sites was achieved in the presence of drug at a higher concentration $(6 \mu \mathrm{M})$. Like for A431 cells (above), these experiments clearly showed that $\mathrm{NaPaC}$ inhibited the $\mathrm{VEGF}_{165}$ binding to HUV-EC cells probably by forming a complex with the growth factor.

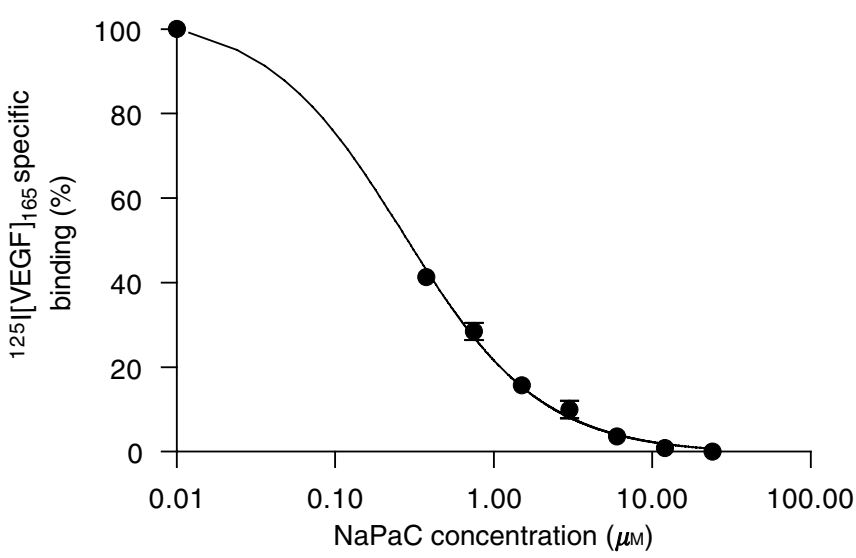

Figure $4 \mathrm{NaPaC}$ inhibits the $\mathrm{VEGF}_{165}$ binding to HUV-EC endothelial cells. Cells were incubated with a fixed concentration of [ $\left.{ }^{125} \mid\right] V E_{165}$ (7 pM) in the absence or presence of $\mathrm{NaPaC}$ at various concentrations $(0.0 \mathrm{l}-24 \mu \mathrm{M})$
Phenylacetate carboxymethyl benzylamide dextran inhibits the A431 xenograft growth more efficiently when administrated early

We evaluated the A431 xenograft growth when $\mathrm{NaPaC}$ administration begun simultaneously with tumour cell inoculation (early treatment, Figure 5, black symbols) and when $\mathrm{NaPaC}$ injection, at the same dose and for the same period of 5 weeks, started 1 week after A431 cell inoculation, when palpable tumours appeared (late treatment, Figure 5, white symbols). Whatever treatment, early or late, a significant inhibition of xenograft growth was observed at the 5th week of $\mathrm{NaPaC}$ administration. However, early $\mathrm{NaPaC}$ treatment reduced the tumour growth by $70 \%$ as compared to control $(P=0.0067)$, whereas late administration of the drug inhibited the A431 tumour growth by $50 \%(P=0.0011)$. Early administration of $\mathrm{NaPaC}$ was not able to affect the A431 tumour uptake. The chronic administration of $\mathrm{NaPaC}\left(15 \mathrm{mg} \mathrm{kg}^{-1}\right)$ to $\mathrm{A} 431$ xenograft-bearing mice, twice a week for 5 weeks, did not cause signs of toxicity. The body weight of mice was not affected. No diarrhoea, infection, weakness or lethargy was stated. All of the 40 studied mice were alive at the end of treatments.

Phenylacetate carboxymethyl benzylamide dextran induces cell death in tumour more effectively when administrated early

In both, early (Figure 6B) and late (Figure 6C), NaPaC-treated tumours, we observed a more intense brown staining of the nuclei of apoptotic cells as well as a more diffused brown staining of the cytoplasm and the nuclei of necrotic cells as compared to control (Figure 6A). Since the difference between the staining of necrotic and apoptotic cells was difficult to distinguish, we counted all brown-stained cells. This statement is in agreement with our recent observations that, in breast cancer xenografts, $\mathrm{NaPaC}$ induced rather aponecrosis (Di Benedetto et al, 2002) described by Formigli et al (2000) than classical apoptosis. In the early treated tumours, large regions of necrosis were observed (Figure 6B) and the number of aponecrotic cells per area was increased by $70 \%$ as compared to control $(P<0.0001)$. In the case of late treatment with $\mathrm{NaPaC}$, the density of aponecrotic cells was increased by $30 \%$

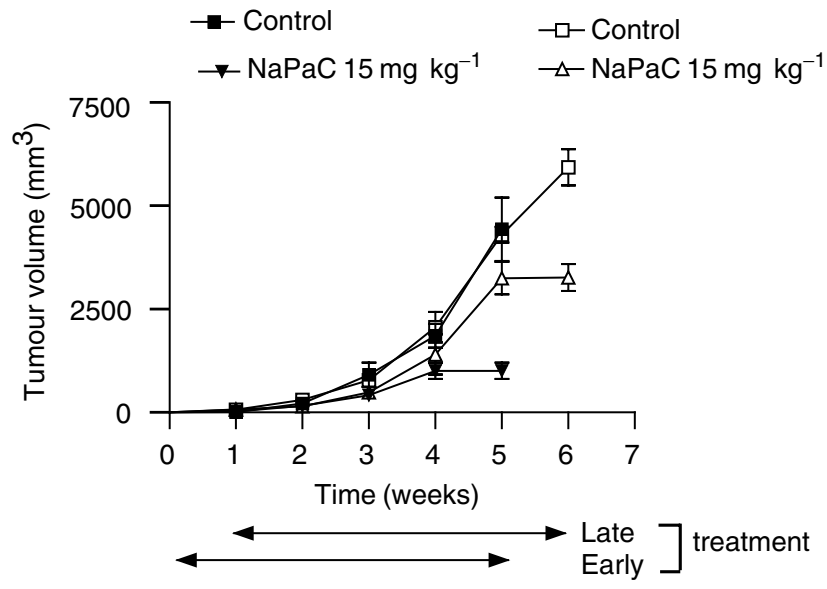

Figure $5 \mathrm{~A} 43 \mathrm{I}$ tumour growth inhibition induced by early and late administrations of $\mathrm{NaPaC}$ in nude mice. Early treatment (black symbols) was performed by a simultaneous s.c. inoculation of A43I cells $\left(1 \times 10^{5}\right)$ at day 0 and $\mathrm{NaPaC}\left(15 \mathrm{mg} \mathrm{kg}^{-1}\right)$. Late s.c. treatment (white symbols) with $\mathrm{NaPaC}\left(15 \mathrm{mg} \mathrm{kg}^{-1}\right)$ began I week after tumour uptake, when tumours were well established $\left(=100 \mathrm{~mm}^{3}\right)$. $\mathrm{NaPaC}$ was injected twice a week for 5 weeks for both early and late treatment. Control groups received $0.1 \mathrm{ml}$ of $0.9 \% \mathrm{NaCl}$ for the same period. Each point represents the mean of tumour volume $\left(\mathrm{mm}^{3}\right) \pm$ s.d. $(n=10)$. 

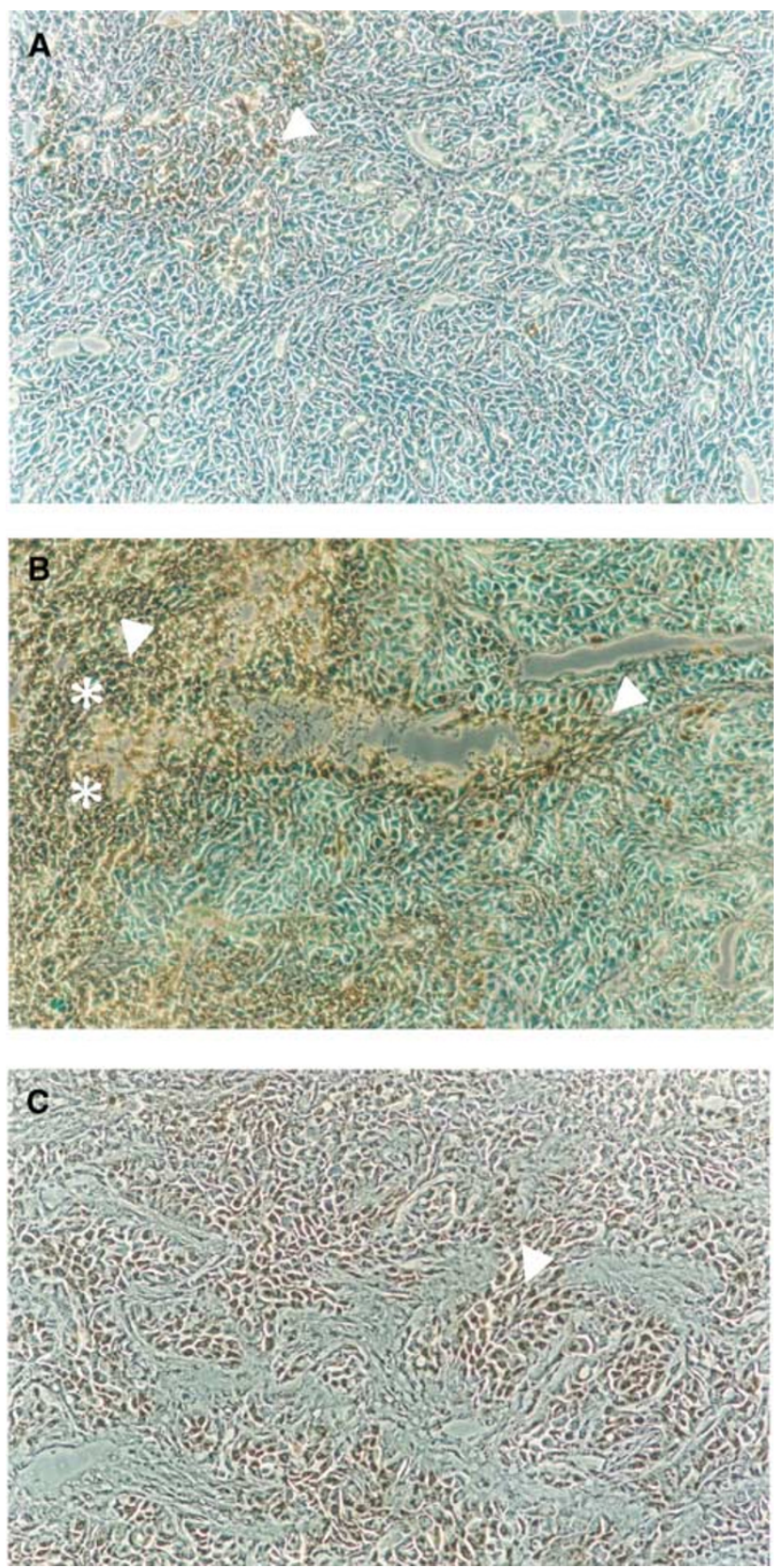

Figure 6 Phenylacetate carboxymethyl benzylamide dextran induces the cell death in early and late treated A43I tumours. Cell death of untreated (A) and early (B) or late (C) treated tumours was assessed by terminal deoxynucleotidyl transferase-mediated nick-end labelling using Tumour TACS kit. Necrotic area was marked with asterisks. Representative aponecrotic cells were marked with arrows.

compared to control $(P<0.0001$, Figure 6C $v s \mathrm{~A})$ and the necrotic regions were diminished as compared to early treated tumours (representative photos shown in Figure 6).

\section{Effect of early- and late-administrated $\mathrm{NaPaC}$ on the microvascular system of A431 tumour}

As we recently demonstrated that $\mathrm{NaPaC}$ inhibited in vitro the growth of human endothelial cells (HUV-EC) (Di Benedetto et al, 2002) and since we showed, in this paper above, that $\mathrm{NaPaC}$ competes with $\mathrm{VEGF}_{165}$ for the binding to endothelial cells, we evaluated the drug effects on microvessel development in A431 tumours (Figure 7). We attempted to operate on vessel network in xenograft at two different stages of its formation by early (Figure 7B) and late (Figure 7D) administration of $\mathrm{NaPaC}$.

The number of endothelial cells per tumour tissue area $\left(1 \mathrm{~mm}^{2}\right)$ was decreased by $50 \%(P=0.006)$ after early $\mathrm{NaPaC}$ administration as compared to control (no treated) and 30\% $(P=0.045)$ after late treatment as compared to corresponding no treated control (Figure 8A). When early treated tumours were compared to late treated ones this parameter was statistically similar. Concerning the fraction of the total tissue area occupied by the wall and/or lumen of vessel (vessel area), $\mathrm{NaPaC}$ was inefficient when used lately as compared to control (Figure $8 \mathrm{~B}$ ), whereas it has an inhibitory effect $(35 \%, P=0.014)$ when injected early. Thus, $\mathrm{NaPaC}$, administrated early, is able to affect the endothelial cell number and vessel area whereas $\mathrm{NaPaC}$, injected late, alters only the first parameter.

\section{DISCUSSION}

In this paper, we showed the antiproliferative, antiangiogenic and aponecrotic action of a new dextran derivative, $\mathrm{NaPaC}$, on fast growing xenografts of A431 cells derived from an aggressive epidermoid carcinoma. A431 cells are known to secrete a large quantity of VEGF (Myoken et al, 1991), a potent angiogenic factor. We recently demonstrated that $\mathrm{NaPaC}$ interacted with $\mathrm{VEGF}_{165}$ by forming a complex and inhibited the proliferation of endothelial cells stimulated by VEGF $_{165}$ (Di Benedetto et al, 2002). Here, we demonstrated, in addition, that $\mathrm{NaPaC}$ inhibited the binding of $\mathrm{VEGF}_{165}$ to its specific receptors on human endothelial cells. In the light of these $\mathrm{NaPaC}$ properties, we attempted to inactivate locally VEGF $_{165}$ secreted by A431 cells at two different steps of xenograft development: by early administration of $\mathrm{NaPaC}$, starting at tumour cell inoculation; and late treatment, beginning 1 week later when tumours were well established. Thus, we could operate on vessel network formation at two different stages. Since the tumour growth was largely demonstrated to be dependent on angiogenesis (Folkman, 1995; Carmeliet and Jain, 2000), we explored the impact of tumour vasculature evolution on the A431 xenograft growth.

In the case of both early and late treatments, $\mathrm{NaPaC}$ strongly inhibited the A431 tumour growth. It is well established now that tumour growth can be affected by tumour cell proliferation, tumour cell death and angiogenesis. Concerning cell proliferation, $\mathrm{NaPaC}$ was shown, here, to inhibit the in vitro A431 growth. This action could involve, at least in part, the decreasing VEGF 165 binding to A431 cells as reported in this study. However, like Melnyk et al (1996), we were not able to evidence a VEGF dependence of A431 cell growth in vitro (data not shown) probably because of the high quantity of the secreted endogenous VEGF (Myoken et al, 1991). In vivo, we found that early $\mathrm{NaPaC}$ administration for 5 weeks was significantly more efficient than late one. Nevertheless, for both treatments, the A431 tumour uptake was observed at the same time after cell inoculation and the difference in growth rate of tumours only became significantly apparent after 4 weeks. In the light of these observations, the difference in effect of early and late $\mathrm{NaPaC}$ treatment cannot be explained considering only direct inhibitory effect of $\mathrm{NaPaC}$ on tumour cell proliferation.

In relation to tumour growth inhibition, we observed an increase in aponecrotic cell density in tumours. Indeed, the cell death was more important in early $\mathrm{NaPaC}$-treated tumours than in late treated ones. Although, in our experimental conditions, we cannot distinguish the tumour and endothelial cells undergoing a death, it is clear that difference observed above is related to variations in the death of rather tumour cells than endothelial ones. The argument supporting this idea is that endothelial cell density was decreased in early and late treated tumours in the same manner. We recently reported that $\mathrm{NaPaC}$ induced in vitro 

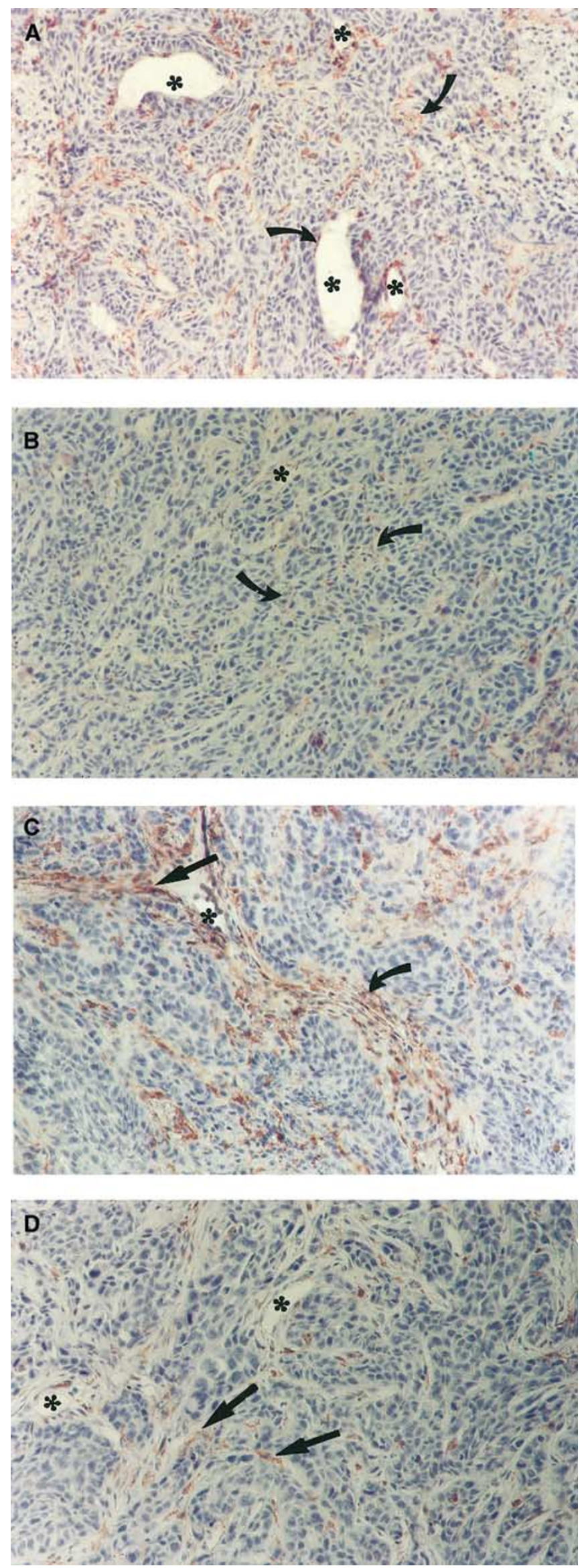
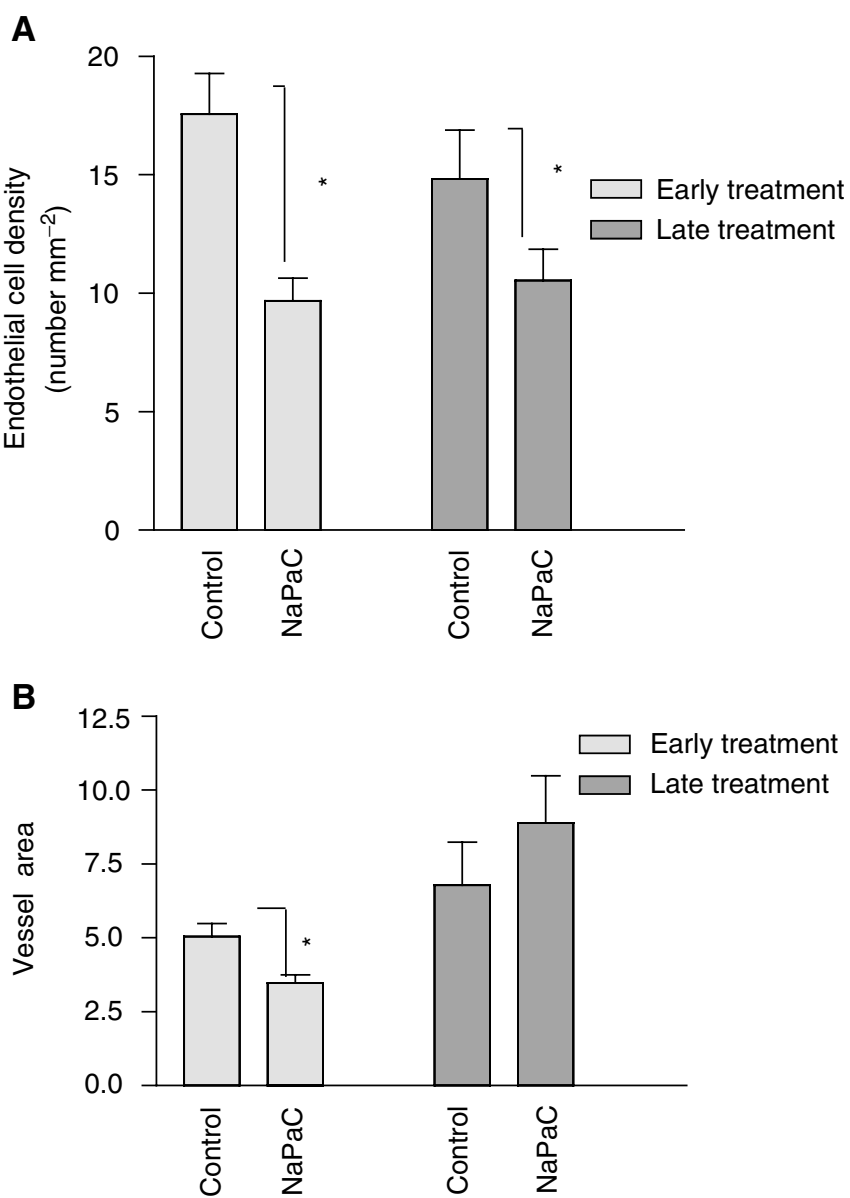

Figure 8 Quantification of endothelial cell density and vessel area in early and late $\mathrm{NaPaC}$-treated tumours. (A) The GSL-I lectin-stained endothelial cells per $\mathrm{mm}^{2}$ of tumour area (endothelial cell density) and (B) the fraction of the total tissue area occupied by the wall or/and lumen (vessel area) was determined as described in Materials and Methods. Each column represents the mean \pm s.d. $(n=10)$. ${ }^{*} P<0.05$ vs control.

the aponecrosis of breast cancer MCF-7ras cells (Di Benedetto et al, 2002) arguing for a possible direct aponecrotic effect of $\mathrm{NaPaC}$ on A431 cells. Nevertheless, in vivo, it is also likely that cell death was generated in tumour, at least in part, by oxygen deprivation of tissue owing to angiogenesis inhibition.

We showed in this report that both early and late treatments with $\mathrm{NaPaC}$ decreased, to the same extent, the endothelial cell density. In contrast, the vessel area, reflecting the overall number and/or size of vessels, was reduced in early treated tumours, whereas it was unchanged in late treated xenografts as compared to control. Thus, the vessel morphology in early and late treated tumours was different. These results showed that $\mathrm{NaPaC}$, injected early, prevents the vessel enlargement and/or the increase in vessel number, these modifications being observed in late (1 week delayed) treated tumours as well as in control ones. Thus, a first week of A431 xenograft development, in the absence of $\mathrm{NaPaC}$, is

Figure 7 Effects of $\mathrm{NaPaC}$ on $\mathrm{A} 43 \mathrm{I}$ tumour microvessel network. Endothelial cells were stained in early $(\mathbf{A})$ and late $(\mathbf{C})$ treatment controls, and in early (B) and late (D) $\mathrm{NaPaC}$-treated tumours using GSL-I lectin. Microvessel lumens in panels were indicated with asterisks. Magnification used was $\times 250$. The representative AEC-stained endothelial cells (red) are indicated with arrows. 
sufficient for morphological changes in intratumour vasculature. Interestingly, even 5 weeks $\mathrm{NaPaC}$ treatment was not able to affect these changes. The morphological transformations of intratumour vessels were recently described (Eberhard et al, 2001, Izumi et al, 2002, Leenders et al, 2002; Ryschich et al, 2002). In particular, it was observed that the early event of tumour angiogenesis consists in dilating the existing vessels prior to their sprouting (Eberhard et al, 2001; Leenders et al, 2002). This finding is in agreement with our observation that the vessel area was higher in late treated tumours, when $\mathrm{NaPaC}$ administration started 1 week after xenograft cell implantation, than in early treated ones, where $\mathrm{NaPaC}$ acted at the beginning of intratumour vasculature formation. As VEGF, produced in large amounts by A431 cells, has also vasodilating activity (Dvorak et al, 1999), it is possible that $\mathrm{NaPaC}$ administrated early was able to inactivate, at least in part, this growth factor and consequently to prevent vessel dilation. Since vessels are present even in the early treated tumours, it could be that A431 cells surround and co-opt, immediately after inoculation, the existing subcutaneous vessels as it was described in the case of non-small-cell-lung carcinoma (Pezzela et al, 1997) and melanoma (Leenders et al, 2002). Moreover, $\mathrm{NaPaC}$ seems to have no effect, administrated early or late, on this phenomenon. However, we cannot discard that in our experimental model the formation of neo-vessels occurs very early and that $\mathrm{NaPaC}$ is not able to inhibit it completely.

Altogether, our results showed that $\mathrm{NaPaC}$ inhibited the $\mathrm{A} 431$ tumour growth acting on both endothelial and tumour cells. The extent of this effect was dependent on the outset of $\mathrm{NaPaC}$ treatment. Since the period of $\mathrm{NaPaC}$ action on A431 cell

\section{REFERENCES}

Avramoglou T, Bagheri R, Chaubet F, Crépin M, Dehri-Correia L, Di Benedetto M, Gervelas C, Huynh R, Jozefonvicz J (2001) Composition pharmacéutique contenant au moins un polymère associé ou conjugué à au moins un seul acide phenylalkylcarboxylique. Polymères conjugués et leurs application. Patent No. WO 0191742

Alroy J, Goyal V, Skutelsky E (1987) Lectin histochemistry of mammalian endothelium. Histochemistry 86: 603-607

Bergers G, Javaherian K, Lo KM, Folkman J, Hanahan D (1999) Effects of angiogenesis inhibitors on multistage carcinogenesis in mice. Science 284: $808-812$

Blood CH, Zetter BR (1990) Tumor interactions with the vasculature: angiogenesis and tumor metastasis. Biochim Biophys Acta 1032: 89-118

Carmeliet P, Jain RK (2000) Angiogenesis in cancer and other diseases. Nature 407: 249-257

Cascinu S, Staccioli MP, Gasparini G, Giordani P, Catalano V, Ghiselli R, Rossi C, Baldelli AM, Graziano F, Saba V, Muretto P, Catalano G (2000) Expression of vascular endothelial growth factor can predict event-free survival in stage II colon cancer. Clin Cancer Res 6: 2803-2807

Di Benedetto M, Kourbali Y, Starzec A, Vassy R, Jozefonvicz J, Perret GY, Crepin M, Kraemer M (2001) Sodium phenylacetate enhances the inhibitory effect of dextran derivative on breast cancer cell growth in vitro and in nude mice. Br J Cancer 85: 917 -923

Di Benedetto M, Starzec A, Colombo BM, Briane D, Perret GY, Kraemer M, Crepin M (2002) Aponecrotic, antiangiogenic and antiproliferative effects of a novel dextran derivative on breast cancer growth in vitro and in vivo. Br J Pharmacol 135: $1851-1858$

Dvorak HF, Nagy JA, Feng D, Brown LF, Dvorak AM (1999) Vascular permeability factor/vascular endothelial growth factor and the significance of microvascular hypermeability in angiogenesis. In Vascular Growth Factors and Angiogenesis, Claesson-Welsch L (ed) pp 97-132. Berlin: Springer-Verlag

Eberhard A, Kahlet S, Goede V, Hemmerlein B, Plate KH, Augustin H (2001) Heterogeneity of angiogeneis and blood vessel maturation in human tumors: implication of antiangiogenic tumor therapies. Cancer Res 60: $1388-1393$

Folkman J (1995) Angiogenesis in cancer, vascular, rheumatoid and other diseases. Nat Med 1: 27-31 proliferation was the same (5 weeks) and since the endothelial cell density was decreased in the same manner in both early and late treated tumours, the most probable is that the difference in tumour growth inhibition was because of changes in intratumour vascular network leading to the increase in tumour cell death observed above. Altogether, our data indicate that A431 xenograft model can be used to study the impact of vascular network in tumour growth and to screen potential antiangiogenic agents.

In conclusion, we demonstrated that $\mathrm{NaPaC}$ potently inhibits fast-growing epidermoid carcinoma by acting on tumour cells and intratumour endothelial cells whatever the state of xenograft development. Nontoxic at efficient doses, $\mathrm{NaPaC}$ provides interesting clues for therapies of solid tumours preventing the vascular network evolution in malignant lesions, thus inhibiting the rapid expansion from small tumours to late-stage tumours. Moreover, its direct inhibitory action on tumour cell proliferation argues for its usefulness in late-stage tumour treatment.

\section{ACKNOWLEDGEMENTS}

We thank Grant sponsors: Ministère de l'Education Nationale; Association pour la Recherche contre le Cancer (Grant no. 9721), La Ligue Nationale contre le Cancer and Biodex Laboratory. We are grateful to Professor A Martin for helpful discussions concerning the histological tumour analysis, Professor M Frojmovic for English corrections, $O$ Sainte-Catherine for excellent technical assistance and $\mathrm{L}$ Correa for $\mathrm{NaPaC}$ preparation. We thank Professor PM Martin for A431 cell gift.
Formigli L, Pappuci L, Tani A, Schiavone N, Tempestini A, Orlandini GE, Capaccioli S, Orlandini SZ (2000) Aponecrosis: morphological and biochemical exploration of a syncretic process of cell death sharing apoptosis and necrosis. J Cell Physiol 182: $41-49$

Izumi Y, Xu L, di Tomaso E, Fukumura D, Jain RK (2002) Herceptin acts as an anti-angiogenic coktail. Nature 416: 279-280

Krantz A, Mattfeldt T, Waltenberger J (1999) Molecular mediators of tumor angiogenesis: enhanced expression and activation of vascular endothelial growth factor receptor KDR in primary breast cancer. Int J Cancer 84: $293-298$

Leenders W, Küster B, de Wall R M W (2002) Vessel co-option: how tumor obtain blood supply in the absence of sprouting angiogenesis. Endothelium 9: 83-87

Li S, Peck-Radosavljevic M, Koller E (2001) Characterization of ${ }^{123} \mathrm{I}-$ vascular endothelial growth factor-binding sites expressed on human tumour cells: possible implication for tumour scintigraphy. Int J Cancer 91: $789-796$

Melnyk O, Shuman MC, Kim KJ (1996) Vascular endothelial growth factor promotes tumor dissemination by a mechanism distinct from ots effect on primary tumor growth. Cancer Res 56: $921-924$

Mori A, Shigeki A, Furutani M, Hanaki K, Takeda Y, Moriga T, Kondo Y, Gorrin Rivas MJ, Imamura M (1999) Vascular endothelial growth factor-induced tumor angiogenesis and tumorigenicity in relation to metastasis in a HT1080 human fibrosarcoma cell model. Int J Cancer 80: $738-743$

Mosmann T (1983) Rapid colorimetric assay for cell growth and survival: application to proliferation and cytotoxicity assays. J Immunol Methods 65: $55-63$

Myoken Y, Kayada Y, Okamoto T, Sato GH, Sato JD (1991) Vascular endothelial cell growth factor (VEGF) produced by A431 human epidermoid carcinoma cells and identification of VEGF membrane binding sites. Proc Natl Acad Sci USA 88: 5819-5823

Pezzela F, Pastorino U, Tagliabue E (1997) Non-small-cell lung carcinoma tumor growth without morphological evidence of neo-angiogenesis. Am J Pathol 151: 739-752

Ramanujan S, Koenig GC, Padera TP, Stoll BR, Jain K (2000) Local imbalance of proangiogenic and antiangiogenic factors: a potential 
mechanism of focal necrosis and dormancy in tumors. Cancer Res 60: $1442-1448$

Ryschich E, Schmidt J, Hämmerling GJ, Klar E, Ganss (2002) Transformation of the microvascular system during multistage tumorigenesis. Int $J$ Cancer 97: 719-725

Scatchard G (1986) The attraction of proteins for small molecules and ions. Ann NY Acad Sci 261: 4660-4662

Senger DR, Peruzzi CA, Feder J, Dvorak HE (1986) A higly conserved vascular permeability factor secreted by a variety of human and rodent tumor cell lines. Cancer Res 46: 5629-5633

Shen GH, Ghazizadeh M, Kwanami O, Shimizu H, Jin E, Araki T, Sugisaki Y (2000) Prognostic significance of vascular endothelial growth factor expression in human ovarian carcinoma. $\mathrm{Br} J$ Cancer 83: $196-203$
Soker S, Fidde H, Neufeld G, Klagsburn M (1996) Characterization of novel vascular endothelial growth factor (VEGF) receptor on tumor cells that bind VEGF ${ }_{165}$ via its exon 7-encoded domain. J Biol Chem 271: 5761 - 5767

Weibel ER (1979) Practical methods for biological morphometry. In Stereological Methods, Weibel ER (ed) 1, pp 1-415. London: Academic Press

Weidner N, Semple JP, Welch WR, Folkman J (1991) Tumor angiogenesis and metastasis correlation in invasive breast carcinoma. $N$ Engl J Med 324: $1-8$

Workman P, Twentyman P, Balkwill F, Balmain A, Chaplin D, Double J, Embleton J, Newell D, Raymond R, Stables J, Stephens T, Wallace J (1998) United Kingdom Co-ordinating Committee on Cancer Research (UKCCCR) Guidelines for the Welfare of Animals in Experimental Neoplasia (Second Edition). Br J Cancer 77: 1 - 10 